\title{
Pituitary-adrenal activity and appetitive reinforcement
}

\author{
A. RANDICH, J. C. FROEHLICH, S. M. FRALEY, J. L. FJERMESTAD, and F. R. BRUSH \\ Experimental Psychology Laboratory, Syracuse University, Syracuse, New York 13210
}

Individual groups of rats were trained to leverpress for either a high or a low rate of food reward. Between-group comparisons of plasma and adrenal corticosterone concentrations were made for groups remaining on their respective reinforcement schedules and groups shifted to extinction. Plasma and adrenal corticosterone concentrations for groups receiving a low rate of food reward were elevated in comparison to those receiving a high rate of food reward. A shift to extinction from a high rate of reinforcement produced a significant increase in plasma and adrenal corticosterone concentration, but no change occurred when the shift was made from a schedule delivering a low rate of reinforcement. Hormone comparisons were also made between two groups of rats working on schedules that differed in preferential value (DRL and VI), but were equated for reinforcement frequency. There was no significant difference in corticosterone concentrations between these two groups, indicating that schedule preference does not influence pituitary-adrenal activity when reinforcement frequency is controlled.

It is well known that the pituitary-adrenal system is activated in a variety of aversive conditioning situations (Coover, Ursin, \& Levine, 1973; De Wied, 1965; Mason, 1959). Recently, Coover, Goldman, and Levine (1971) and Goldman, Coover, and Levine (1973) also showed activation of this system in appetitive situations. Rats responding on fixed ratio (FR), variable interval (VI), or continuous reinforcement (CRF) schedules of water reward showed elevations of plasma corticosterone concentrations when they were shifted to schedules which delivered lower frequencies of reward. In contrast, shifts to schedules which delivered higher frequencies of reward decreased plasma corticosterone concentration. However, when frequency of reward was held constant, shifts from a highly predictable (FI) to a less predictable (VI) schedule elevated plasma corticosterone concentration (Levine, Goldman, \& Coover, 1972. Therefore, it may be hypothesized that activity of the pituitary-adrenal system in appetitive situations is influenced by changes in expectancy or predictability of reward as well as by changes in reward frequency.

Schedules that differ in their preference value may also differentially activate the pituitary-adrenal system. For example, Mason (1959) found that a VI schedule produced a small within-session decrease in plasma 17-OHCS levels in monkeys, whereas a DRL (differential reinforcement of low

This research was supported in part by a grant from the Syracuse University Senate Research Committee to F. R. Brush. Reprint requests should be sent to F. R. Brush, Experimental Psychology Laboratory, Archbold Stadium, Syracuse University, Syracuse New York, 13210. A. Randich is now at Psychology Department, Dalhousie University, Halifax, Nova Scotia, Canada. J. L. Fjermestad is now at Psychology Department, SUNY, Cortland, New York. rate) schedule produced a significant within-session increase in plasma 17-OHCS. A variety of behavioral data suggests that DRL schedules are relatively aversive and that animals prefer VI to DRL schedules even when reinforcement frequency is controlled (Catania, 1966; Fantino, 1968; Kramer \& Rilling, 1970; Premack, 1969; Shimp, 1966). Thus, this difference in preference for the schedules used by Mason may account for the reported differential pituitary-adrenal response. However, in the Mason study reward frequency was undoubtedly confounded with the difference in schedule preference. Similarly, the hormonal effects which Goldman et al. (1973) attributed to changes in expectancy or frequency of reinforcement may also be due to changes in schedule preference, since many of the manipulations in their experiments involved shifts to more- or less-preferred schedules. Thus, further experiments are needed to separate the effects of preference, expectancy, and/or predictability of reinforcement, and reinforcement frequency on pituitary-adrenal activity.

The following experiments were designed (1) to investigate the extent to which frequency and expectancy of reward influences pituitary-adrenal activity, and (2) to determine whether various schedules of reinforcement (shown to differ in preference value in other behavioral tests) result in differential activation of the pituitary-adrenal system system.

\section{EXPERIMENT I}

This experiment investigated whether differences in plasma and adrenal corticosterone concentration would be found (1) between groups of subjects 
responding on VI schedules that differed in frequency of reinforcement, and (2) when subjects responding on these schedules were shifted to an extinction procedure.

Coover et al. (1971) and Goldman et al. (1973) used a within-subject sampling procedure over the various stages of training. This involved anesthetizing the animal with ether and drawing a blood sample from the jugular vein within $2.5 \mathrm{~min}$ following a test session. Although it has been reported (Davidson, Jones, \& Levine, 1968) that this sampling procedure did not itself induce an elevation in plasma corticosterone within $2.5 \mathrm{~min}$, Sakellaris and Vernikos-Danellis (1974) did find a significant adrenal response within $2.5 \mathrm{~min}$ following an injection stress if the animals were adapted to a water-deprivation schedule. In order to eliminate such interactions between the sampling procedure and deprivation schedule, we used a between-groups design in which blood samples were obtained by decapitation. Since Coover et al. (1971) and Goldman et al. (1973) used water deprivation and water reward, we wished to extend the generality of their findings to schedule manipulations using food deprivation and reward.

Method
Subjects
Twenty-five experimentally naive, male, Long-Evans rats from
the Experimental Psychology Laboratory animal colony at
Syracuse University served as subjects. They were $80-90$ days
old at the start of the experiment and were housed individually
in a room with automatically controlled illumination which
cycled on at 0700 and off at $1900 \mathrm{~h}$.

\section{Apparatus}

Four Predco operant conditioning units $(27 \times 38 \times 22 \mathrm{~cm})$ mounted in sound-attenuating chambers were used. Noyes food pellets $(45 \mathrm{mg})$ were automatically delivered to the food hopper located directly beneath the lever. Depression of the lever required approximately $0.12 \mathrm{~N}(15 \mathrm{~g})$ to activate the microswitch. General chamber illumination was provided by a $15-\mathrm{W}$ light, and extraneous sounds were masked by ventilating fans at an ambient level of $68 \mathrm{~dB}$ (SPL). Variable interval schedules were generated by standard tape programmers and relays. Responses and reinforcements were recorded on counters and cumulative recorders.

\section{Procedure}

Decapitation. Sacrifice was by decapitation at times indicated in each experiment, and trunk blood was collected in heparinized tubes, centrifuged and plasma stored frozen.

Bilateral adrenalectomy. Bilateral adrenalectomy was performed immediately following sacrifice and involved a dorsal midline incision of the skin and bilateral abdominal incisions. The adrenals were removed, trimmed of fat, weighed, and homogenized in $+\mathrm{m}$ ! of $20^{\circ}$ o cthanol- $0.9^{\circ} \mathrm{NaCl}$ solution. The homogenate was frozen and stored.

Plasma and adrenal determinations of corticosterone. Before corticosterone determinations were made, precipitated protein was removed from the thawed plasma samples and the thawed adrenal homogenates were centrifuged. Plasma and adrenal corticosterone concentrations were determined in duplicate using a modification of the Glick, Von Redlich, and Levine (1964) micro version of the Zenker and Bernstein (1958) fluorometric technique. Blanks and standard concentrations of corticosterone were included in each set of determinations. Percent recovery in fortified samples were $105 \%$ and $115 \%$ for plasma and adrenal concentrations, respectively. Significant overestimates occurred only when small (less than $5.00 \mu \mathrm{g}$ ) amounts of corticosterone were involved.

Experimental design. The subjects were reduced to and maintained at $70 \%-80 \%$ of their free-feeding weights over a period of 10 days. Water was available ad lib. Food-deprivation controls were maintained at $70 \%-80 \%$ normal body weight over the course of the experiment and remained at all times in their home cages except for weighing. Feeding never occurred before $1530 \mathrm{~h}$.

The experimental subjects were magazine trained and placed on a CRF schedule until a criterion of 50 reinforced barpresses was met. After this preliminary training, they were randomly assigned to one of two groups: VI $30 \mathrm{sec}(\mathrm{N}=10)$ and VI $5 \mathrm{~min}$ $(N=10)$. Animals in the VI 5 -min group received, in addition, 1 or 2 days of training on VI $30 \mathrm{sec}$ in order to ease their transition from CRF to the VI 5-min schedule. The experimental subjects then remained on their assigned schedules for 11 days, and on Day 12, half of the subjects in each group were placed on extinction (VI 30 Ext and VI 5 Ext, respectively), while the other half (VI 30 and VI 5, respectively) remained on their assigned schedules to serve as controls for their corresponding extinction group. Following the session on Day 12, all subjects were removed from the testing apparatus and decapitated within $30 \mathrm{sec}$. All training session were $30 \mathrm{~min}$ in duration, and the experimental animals were fed immediately after the training session. There were five subjects in the food-deprived control group, and they were decapitated at different times over the course of the experimental sessions on Day 12. All decapitations occurred between 0700 and $1100 \mathrm{~h}$. In a separate experiment, it was found that plasma corticosterone concentrations were low and relatively constant during this time period and that the circadian elevation of plasma corticosterone did not begin until around $1300-1400 \mathrm{~h}$.

\section{Results and Discussion}

Table 1 presents the medians and ranges of plasma $(\mu \mathrm{g} / 100 \mathrm{ml})$ and adrenal $(\mu \mathrm{g} / \mathrm{g})$ corticosterone concentrations for all groups on the day of sacrifice, and significant differences are indicated. Skewed distributions required the use of nonparametric measures, and group comparisons were made using the Mann-Whitney U test for independent groups.

A significant elevation in both plasma and adrenal corticosterone concentration was found in all experimental groups compared to the food-deprived control group. These findings contrast with those of Coover et al. (1971) and Goldman et al. (1973), who used water deprivation in a within-subjects design. They found no significant elevation in plasma corticosterone following reinforced sessions relative to presession levels.

Plasma and adrenal levels in the VI 5 group were significantly greater than those in the VI 30 group. Table 2, which presents mean response rates for the groups on Days 11 and 12, shows that on both days the response rate of the VI 5 group was roughly half that of the VI 30 group. If activity (response rate) and pituitary-adrenal activity are directly related (Sayers \& Sayers, 1948), the more active group (VI 30) would be expected to have higher plasma and adrenal corticosterone concentrations than the less active group (VI 5). The converse was clearly found. Thus, the difference in plasma and adrenal corticosterone levels in these unshifted 
Table 1

INumber of Subjects, Group Medians, and Ranges of Plasma $(\mu \mathrm{g} / 100 \mathrm{ml})$ and Adrenal $(\mu \mathrm{g} / \mathrm{g})$ Corticosterone Concentrations for All Groups on Day 12

\begin{tabular}{|c|c|c|c|c|c|c|}
\hline & \multicolumn{3}{|c|}{ Plasma $(\mu \mathrm{g} / 100 \mathrm{ml})$} & \multicolumn{3}{|c|}{ Adrenal $(\mu \mathrm{g} / \mathrm{g})$} \\
\hline & $\mathrm{N}$ & Median & Range & $\mathrm{N}$ & Median & Range \\
\hline $\begin{array}{l}\text { Food Deprived } \mathbf{1} \\
\text { VI } 30^{2} \\
\text { VI } 30 \mathrm{Ext} \\
\text { VI } 5 \\
\text { VI } 5 \mathrm{Ext}\end{array}$ & $\begin{array}{l}4 \\
4 \\
5 \\
5 \\
5\end{array}$ & $\begin{array}{l}6.9 \\
28.6 * \dagger \\
40.0^{*} \ddagger \\
38.5 * \dagger \\
34.0 *\end{array}$ & $\begin{array}{r}3.0-20.0 \\
22.5-34.8 \\
32.8-52.0 \\
26.2-44.8 \\
26.5-49.8\end{array}$ & $\begin{array}{l}4 \\
4 \\
5 \\
5 \\
5\end{array}$ & $\begin{array}{l}\quad 6.7 \\
41.8^{*} \dagger \\
48.7^{*} \\
57.7^{*} \dagger \\
48.8^{*}\end{array}$ & $\begin{array}{r}6.0-8.2 \\
33.1-50.3 \\
44.3-58.2 \\
47.2-65.7 \\
29.0-57.8 \\
\end{array}$ \\
\hline
\end{tabular}

1. One subject was dropped on the basis of a significantly elevated adrenal concentration ( $p \leqslant .005$; studentized test of extreme deviation, Diem and Lentner, 1972).

2. One subject was dropped because the plasma was lost during centrifugation of the blood sample.

$* \quad p \leqslant .01$ in comparison to food-deprived control group

$\dagger p \leqslant .03 ;$ groups significantly different

$\ddagger p \leqslant .02$ in comparison with VI 30 group

controls cannot be accounted for by the difference in activity level. Indeed, the obtained differences in corticosterone levels may underestimate the true effect of these schedules on pituitary-adrenal activity. Rank-order correlations between plasma corticosterone levels and response rate on Day 12 in these unshifted control groups were not significant. Therefore, it would appear that the difference in pituitaryadrenal activity between the VI 30 and VI 5 groups reflects an effect of absolute frequency of reinforcement.

A significant elevation in plasma and a near significant $(p=.056)$ elevation in adrenal corticosterone concentration was found in the VI $30 \mathrm{Ext}$ group relative to their unshifted controls (VI 30). In contrast, the VI 5 Ext group was not different from their unshifted controls (VI 5) in either plasma or adrenal corticosterone concentration. This difference in the effect on the pituitary-adrenal system of a shift to extinction cannot be attributed to the presence or absence of an extinction effect under the two baseline conditions. The response rates on Day 12 in the VI 30 Ext and VI 5 Ext groups (see Table 2) decreased significantly $(p<.01)$ in both cases. This suggests that the shifts, although representing a greater change in reinforcement frequency in the VI 30 Ext than in the VI 5 Ext group, was nonetheless discriminable in both cases.

However, the percent reduction in response rate in extinction was somewhat greater in the VI 30 Ext group $(31 \%)$ than in the VI 5 Ext group $(25 \%)$. Thus, the differential pituitary-adrenal activity induced by the shift to extinction from a VI 30 as opposed to

Table 2

Mean Response Rates (per Minute) for All Groups on Days 11 and 12

\begin{tabular}{lcccc}
\hline & VI 30 & VI 30 Ext & VI 5 & VI 5 Ext \\
\hline Day 11 & 21.4 & 21.8 & 12.6 & 10.4 \\
Day 12 & 20.2 & $15.0^{*}$ & 12.6 & $7.8^{*}$ \\
\hline
\end{tabular}

*Groups shifted to extinction on Day 12; all other values are from sessions on the designated VI baseline. a VI 5 baseline may reflect both the relative change in reinforcement frequency and the differential effect on response rate that the change in reinforcement frequency induces. The failures to find a significant pituitary-adrenal response in the VI 5 Ext group contrasts with the consistent pituitary-adrenal responses reported by Goldman et al. (1973) when CRF, VI $12 \mathrm{sec}$, or FR 20 were shifted to extinction. However, it should be noted that in the Goldman et al. experiments, all groups were working on schedules that produced relatively high rates of reinforcement [1.7-22.0 reinforcements per minute $(\mathrm{rft} / \mathrm{min})]$. In the present experiment, a significant response was also found in the VI 30 Ext group, which had a comparably high rate of reinforcement ( $2.0 \mathrm{rft} / \mathrm{min}$ on baseline), but no response occurred when the baseline rate of reinforcement was low $(0.2 \mathrm{rtt} / \mathrm{min}$ in VI 5$)$. Thus, although extinction following schedules having either a high or low rate of reinforcement affects behavior, i.e., it induces lower response rates, a shift to extinction from certain partial reinforcement schedules may not be a sufficient condition for pituitary-adrenal activation.

\section{EXPERIMENT II}

As noted previously, schedules that differ in preferential value may differentially affect the pituitaryadrenal system. However, in experiments which compare the effects of such schedules (Mason, Brady, \& Sidman, 1957) frequency of reinforcement is often confounded with the presumed difference in preference. In this experiment, we compared the pituitary-adrenal response to two schedules (VI and DRL), one of which (VI) is preferred to the other (DRL). By yoking the VI subjects to the DRL subjects, frequency of reinforcement can be controlled, thus permitting an assessment of the effect of preference on pituitary-adrenal activity.

\section{Subjects}

\section{Method}

Nineteen experimentally naive, male, Long-Evans rats from 
the Experimental Psychology Laboratory animal colony at Syracuse University served as subjects. The age of the subjects and their housing and maintenance arrangements were the same as in Experiment 1 .

\section{Apparatus}

The apparatus was the same as that in Experiment $\mathrm{I}$.

\section{Procedure}

Corticosterone determinations and procedures for sample collection as well as preliminary magazine training, CRF barpress training, and food deprivation routines were as described in Experiment I.

By gradually increasing the interresponse time (IRT) requirement, six subjects were shaped to a DRL 15-sec schedule of food reinforcement over a period of 11 days. Six other subjects were simply maintained at their $70 \%-80 \%$ normal body weights for those 11 days. On Day 12, these six subjects were individually yoked to a DRL partner and both remained yoked on this schedule for 14 days. Reinforcement opportunity for the yoked subjects was contingent upon the DRL partner emitting an IRT of $15 \mathrm{sec}$ or greater: the yoked subjects were required to press their lever to obtain the reinforcement set up by their DRL partner. Thus, they were responding on what amounted to a VI schedule of reinforcement and frequency of reinforcement was equated for a yoked pair. All training sessions were $60 \mathrm{~min}$ in duration, and the experimental subjects were trained in three squads, initially beginning at $1600 \mathrm{~h}$. Beginning on Day 13 and on alternate days thereafter, the training sessions began $2 \mathrm{~h}$ earlier so that by Day 20 training began at $0800 \mathrm{~h}$. The experimental animals were fed immediately after their daily training session. Following the session on Day 25, all subjects were immediately decapitated.

There were seven food-deprived control subjects, which were maintained as in Experiment $I$ at $70 \%-80 \%$ of their normal body weights throughout the course of the experiment. Their feeding occurred as in Experiment I, and they were decapitated on Day 25 between 0900 and $1200 \mathrm{~h}$ when the experimental subjects were also decapitated.

\section{Results and Discussion}

Table 3 presents the medians and ranges of plasma $(\mu \mathrm{g} / 100 \mathrm{ml})$ and adrenal $(\mu \mathrm{g} / \mathrm{g})$ corticosterone concentrations for all groups on the day of sacrifice. Group comparisons again were made using the Mann-Whitney $U$ test for independent groups, and significance levels of various group comparisons are indicated in the table.

No significant effects of the experimental treatments relative to food-deprived controls were found in the plasma concentrations of corticosterone. However, both schedules induced significant elevations in adrenal corticosterone concentration in comparison to the food-deprived control group. This discrepancy between the effects of these treatments on the adrenal as opposed to the plasma estimates of pituitaryadrenal activity cannot easily be explained.

No significant differences were found between DRL and yoked subjects in either plasma or adrenal corticosterone concentrations, although the response rates of the DRL group on Day 25 were significantly lower $(p<.025)$ than those of the yoked (VI) control group (5.0 and 12.9 mean responses/min, respectively). Since these schedules differ in preferential value but not in frequency of reinforcement, this result suggests that schedule preference may not be
Table 3

Number of Subjects, Group Medians, and Ranges of Plasma $(\mu \mathrm{g} / 100 \mathrm{ml})$ and Adrenal $(\mu \mathrm{g} / \mathrm{g})$ Corticosterone Concentrations for All Groups on Day 25

\begin{tabular}{|c|c|c|c|c|c|c|}
\hline & \multicolumn{3}{|c|}{ Plasma $(\mu \mathrm{g} / 100 \mathrm{ml})$} & \multicolumn{3}{|c|}{ Adrenal $(\mu \mathrm{g} / \mathrm{g})$} \\
\hline & $\mathrm{N}$ & Median & Range & $\mathrm{N}$ & Median & Range \\
\hline Food Deprived & 7 & 19.0 & $4.5-25.8$ & 7 & 12.9 & $6.3-35.6$ \\
\hline DRL $15^{1}$ & 5 & 22.0 & $17.5-26.5$ & 5 & $39.4 *$ & $20.9-48.1$ \\
\hline Yoked VI ${ }^{1}$ & 5 & 23.2 & $12.8-34.5$ & 5 & $31.8 *$ & $22.2-38.7$ \\
\hline
\end{tabular}

1. One subject was dropped because either the plasma or adrenal sample was lost during centrifugation.

${ }^{*} p \leqslant .04$ in comparison to food-deprived control group

a significant factor in pituitary-adrenal activity when reinforcement frequency is controlled.

\section{GENERAL DISCUSSION}

Previous studies (Coover et al., 1971; Goldman et al., 1973) have shown that reliable increases in plasma corticosterone occur in response to shifts to extinction from various schedules of reinforcement. These investigators concluded that a shift to extinction from certain partial reinforcement schedules (VI $12 \mathrm{sec}$ and FR 20) is as effective in activating the pituitary-adrenal system as is a shift to extinction from a CRF schedule. The results of the present study indicate that this is not true of all partial reinforcement schedules because when shifts to extinction were made from different VI schedules, the magnitude of the pituitary-adrenal response to extinction from the VI 30 -sec baseline involved a greater change in the rate of reinforcement (2.0$0.0 \mathrm{rft} / \mathrm{min}$ ) than the VI 5 -min baseline shifted to extinction $(0.2-0.0 \mathrm{rft} / \mathrm{min})$. This was reflected by elevations in plasma and adrenal corticosterone concentrations in the VI 30 Ext group and no change in either plasma or adrenal concentration in the VI 5 Ext group. It is possible, however, that given the elevated plasma corticosterone value in the VI 5 group compared to the VI 30 group, a shift to extinction from a VI 5-min schedule may not represent a sufficiently strong stimulus to further activate the pituitary-adrenal system.

There was a discrepancy between plasma corticosterone values of the food-deprived control groups of Experiments I and II $(6.9$ vs. $19.0 \mu \mathrm{g} / 100 \mathrm{ml}$, respectively). This discrepancy cannot be easily explained. Krieger (1974) has shown that when access to food and water is restricted for 15 days to a $2-\mathrm{h}$ period in the morning ( $1.5 \mathrm{~h}$ after lights on) there is a shift in the circadian peak of plasma corticosterone from the period preceding the onset of dark to the period preceding the daily feeding and watering. In our experiments, all blood samples were taken in the morning, which coincided with the usual postsession feeding time of the experimental groups, whereas the food-deprived control groups had 
previously been fed in the late afternoon. Therefore, sampling of the control groups occurred several hours before their normal feeding time. Thus, the very low corticosterone levels of the control group in Experiment I may reflect entrainment of the circadian peak of plasma corticosterone to the afternoon feeding time. However, the higher values of the fooddeprived control group of Experiment II cannot be accounted for by this mechanism. To the extent that feeding entrained the circadian peak in plasma corticosterone in our experimental animals, the observed values reflect the combined effects of the reinforcement schedules per se and the circadian entrainment. It should be noted that the VI $30-\mathrm{sec}$ and VI 5-min groups of Experiments I were above the prefeeding levels reported by Krieger, which suggests that these reinforcement schedules had an effect over and above that of the entrainment of the circadian cycle. Furthermore, the two schedules activated the pituitary-adrenal system differentially.

The data from the unshifted control groups of Experiment I and the DRL and yoked control groups of Experiment II showed that all schedules used in these experiments activated the pituitary-adrenal system and that the magnitude of this effect was inversely related to the rate of reinforcement on the baseline schedule. The effects of these schedules based on food deprivation and food reward are comparable to those reported by Coover et al. (1971) and Goldman et al. (1973) using water deprivation and reward.

The failure to find a pituitary-adrenal response to a DRL schedule, over and above that produced by the rate of reinforcement, is surprising in view of the large volume of behavioral data which suggests that DRL schedules are aversive. This suggests that when rate of reinforcement is controlled and an organism is not given a choice between two schedules, there is no greater pituitary-adrenal response associated with the less preferred (more aversive) schedule. However, this would not preclude a significant pituitary-adrenal response to a DRL schedule if an organism were shifted to that schedule from a more preferred one or if the organism were working in a concurrent choice or multiple schedule situation which would permit comparison between more or less preferred schedules.

\section{REFERENCES}

Catania, A. C. Concurrent operants. In W. K. Honig (Ed.), Operant behavior: Areas of research and application. New York: Appleton-Century-Crofts, 1966. Pp. 213-270.
Coover, G. D., Goldman, L., \& Levine, S. Plasma corticosterone increases produced by extinction of operant behavior in rats. Physiology and Behavior, 1971, 6, 261-263.

Coover, G. D., Ursin, H., \& Levine, S. Plasma corticosterone during active avoidance learning. Journal of Comparative and Physiological Psychology, 1973, 82, 170-174.

Davidson, J. M., Jones, L. E., \& Levine, S. Feedback regulation of adrenocorticotropin secretion in "basal" and "stress" conditions: Acute and chronic effects of intrahypothalamic corticoid implantation. Endocrinology, 1968, 82, 655-663.

DE WIED, D. The influence of the posterior and intermediate lobe of the pituitary and pituitary peptides on the maintenance of a conditioned avoidance response in rats. International Journal of Neuropharmacology, 1965, 4, 157-167.

DiEm, K., \& Lentner, C. (Eds.) "Studentized" test for extreme scores. In Geigy scientific tables. Basle: Ciba-Geigy Ltd., 1972. Pp. 170-171.

Fantino, E. Effects of required rates of responding upon choice. Journal of the Experimental Analysis of Behavior, 1968, 11. 15-22.

Glick, D., Von Redlich, D., \& Levine, S. Fluorometric determination of corticosterone and cortisol in 0.02-0.05 milliliters of plasma or submilligram samples of adrenal tissue. Endocrinology, 1964, 74, 653-655.

Goldman, L., Coover, G. D., \& Levine, S. Bidirectional effects of reinforcement shifts on pituitary-adrenal activity. Physiology and Behavior, 1973, 10, 209-214.

Kramer, T. J., \& Rilling, M. Differential reinforcement of low rates: A selective critique. Psychological Bulletin, 1970, 74. 225-240.

KRIEGER, D. T. Food and water restriction shifts corticosterone, temperature, activity and brain amine periodicity. Endocrinology, 1974, 95, 1195-1201.

Levine. S., Goldman, L., \& Coover, G. D. Expectancy and the pituitary-adrenal system. Ciba Foundation Symposium (Vol. 8) Physiology, emotion and psychosomatic illness. Amsterdam: Elsevier, 1972. Pp. 281-296.

Mason, J. W., Brady, J. V., \& Sidman, M. Plasma 17-hydroxycortico-steroid levels and conditioned behavior in the rhesus monkey. Endocrinology, 1957, 60, 741-752.

MAson, J. W. Psychological influence on the pituitaryadrenocortical system. Recent Progress in Hormone Research, 1959, 15, 345-389.

PremaCK, D. On some boundary conditions of contrast. In J. T. Tapp (Ed.), Reinforcement and behavior. New York: Academic Press, 1969. Pp. 122-145.

Sakellaris, P. C., \& Vernikos-Danellis, J. Alteration of pituitary-adrenal dynamics induced by a water deprivation regimen. Physiology and Behavior, 1974, 12, 1067-1070.

SAYERS, M. A., \& SAYERs, G. The pituitary system. Recent Progress in Hormone Research, 1948, 2, 81-115.

Shimp, C. P. Probabilistically reinforced choice behavior in pigeons. Journal of the Experimental Analysis of Behavior, 1966. 11, 271-284.

Zenker, N., \& Bernstein, D. E. The estimation of small amounts of corticosterone in rat plasma. Biological Chemistry, 1958, 23, 695-701.
(Received for publication December 17, 1975; revision accepted May 5, 1976.) 